\title{
Suspensão narrativa e fluxo temporal. A experiência musical em Tatuagem (2013), de Hilton Lacerda
}

Amanda Mansur Custódio Nogueira

Universidade Federal de Pernambuco, Brasil

\begin{abstract}
The cinematographic production in the city of Recife, in the northeast of Brazil, outlines a dramaturgy that coexists with the musical and cultural scene effervescence that emerged in the city, since its revival in the 90's. Contemporary cinema deliberately explores the mimicry of music in its narrative films when appropriating certain songs, materializing them in sequences of musical interpretation, whose function is the suspension of the narrative. Based on the premise that cinema is organized as a system of languages, inserted within a socio-cultural context, our aim is to investigate the articulating role of music in the local cinema from the analysis of sound/ visual procedures in the narrative construction of the film Tattoo (2013), by Hilton Lacerda, in which the manipulation of cinematic texture intensifies the sensitive musical experience.
\end{abstract}

Keywords: Cinema, Recife, Musical Scene, Film Language, Film Music

\section{Introdução}

Qual o impacto do movimento musical Manguebeat ${ }^{1}$ na retomada da produção cinematográfica na cidade do Recife? Como nessa filmografia a música frequentemente define as escolhas dos ângulos de câmera, a performance dos personagens, a montagem e articula a própria narrativa dos filmes? É com o intuito de debater sobre tais questões que propomos esta comunicação.

Levando em consideração a ligação do cinema com as outras artes (Bazin 2013) e a relação entre a cena musical e a produção audiovisual, usaremos como estudo de caso o filme, Tatuagem (2013), de Hilton Lacerda, para investigar a conexão entre a música e cinema na construção narrativa de filmes realizados em Recife, capital de Pernambuco, Brasil.

O roteirista e diretor pernambucano, Hilton Lacerda, faz parte da geração que retomou a produção cinematográfica no estado e desde o início de sua carreira estabeleceu um intenso diálogo com os músicos da cena. O cinema produzido em Pernambuco, a partir do longa Baile Perfumado (1997), o chamado "Árido Movie", era considerado pelos cineastas como o Manguebeat em forma de cinema.

Nesse sentido, o que nos interessa aqui é justamente investigar a relação da música nos filmes como experiência sinestésica e experiência narrativa. Nossa intenção é observar no filme Tatuagem quais os diálogos e interferências que a música promove na sua construção narrativa.

\section{A Cena Audiovisual}

A produção cinematográfica contemporânea em Recife se organiza em torno de um ethos, uma condição dos discursos fílmicos que vincula as imagens e os sons aos cineastas e à um universo musical compartilhado. Cada filme enuncia um conjunto de realidades que sintonizam de forma particular os cineastas e seus espectadores. As imagens e sons, decorrentes dessa produção, são como liames com um lugar que é, em geral, circunscrito à cidade do Recife.

Cada filme é, portanto, uma apresentação do cineasta individualmente (porque se trata, obviamente, de um conjunto heterogêneo de propostas), mas igualmente uma apresentação de um grupo ${ }^{2}$, localizado num contexto muito específico de produção, que caracterizamos aqui, como brodagem. O termo brodagem começou a ser utilizado para expressar um modo de fazer de produzir algo em parceria (música, cinema, artes plásticas), na década de 1990, no Recife. A gíria pernambucana é um aportuguesamento da palavra em inglês brother, e surge como forma de designar uma irmandade, no caso de um grupo de amigos, ou uma camaradagem, no caso de um favor (Nogueira 2014).

Filmes, no caso, são formas de expressão de algo que vai para além das histórias que são contadas, seja nos documentários, seja nas obras de ficção. Então, esse conjunto de filmes é a revelação de um esquema coletivo, capaz de evocar imagens e sons que antecedem e que sobrevivem a cada um dos filmes.

A cooperação entre os membros do grupo de realizadores de diferentes gerações da cena audiovisual, que atuam concomitantemente na cidade, pode ser definida como uma troca em que as partes se beneficiam (Sennett 2012, 15). É justamente essa estrutura de organização social de um esquema de brodagem, que garante a existência de um cinema em Recife. Distantes do eixo Rio-São Paulo, geograficamente e economicamente falando, os cineastas não tinham outra opção, a não ser se unir, apoiando-se reciprocamente, e cooperando, para conseguir o que não poderiam alcançar sozinhos.

Para Will Straw (2002), as cenas são tratadas como elementos fenomenais na vida cultural das cidades. Memoráveis e efêmeras, as cenas conjugam uma história de lugares urbanos, decretando uma visibilidade dramática. Elas são a medida do declínio, vitalidade e clareza de uma cidade: 
Scenes treating these as phenomenal elements in the cultural life of cities. Both memorable and ephemeral, scenes conjugate a history of urban places by enacting a dramatic visibility. They are a measure of the decline, vitality and distinctness of a city. A century or more of theorizing has subdivided city cultures into communities, subcultures, networks and innumerable other unities. Scenes are both the haziest of such unities and some of the most productive. Amidst an explosion of writing on all aspects of urban culture, our focus on scenes has served to constrain and inspire the studies contained in this issue (Straw, 2002, 1).

A cena é ligada à cidade, na medida em que as cidades são pensadas para ser lugares criadores de cenas, onde elas são fertilizadas. A cena, como forma social, na mistura das funções públicas e privadas em espaços de uma cidade, depende de uma certa teatralidade, exigindo o desempenho dos seus moradores. Por outro lado, se uma cena aponta para uma característica recorrente de uma cidade (como é o caso da cena audiovisual na cidade do Recife), então uma função universal é distribuída de forma diferente. A cena ressoa como uma atividade concreta, uma atividade articulada, diferenciada, e não necessariamente secreta. Pelo contrário, na cena audiovisual na cidade, mesmo sendo legitimada, existem elementos de sigilo, diferenciados do que se propaga. Ou seja, há uma aura esotérica conectada com qualquer cena que muitas vezes torna o conhecimento de seu paradeiro um problema para pessoas de fora ou para aqueles que são novos na cidade, como é o caso da estrutura da brodagem.

O discurso cinematográfico se apoia em uma tecnologia que afeta consideravelmente seus mecanismos enunciativos. $\mathrm{Na}$ linguagem cinematográfica, a enunciação é construída por um aparato de que o realizador vai se apropriar para articular os elementos do filme às relações que vai estabelecer com o espectador. Para Pasolini (1988), o cinema tem uma dupla natureza: é ao mesmo tempo extremamente objetivo e extremamente subjetivo. Utiliza-se dos objetos (signos) para operar em um nível metafórico (simbólico). Em Heretical Empiricism (1988), Pasolini disserta sobre a representação no cinema.

The filmmaker chooses a series of objects, or things, or landscapes, or persons as syntagmas (signs of a symbolic language) which, while they have a grammatical history invented in that moment - as in a sort of happening dominated by the Idea of selection and montage - do, however, have an already lengthy and intense pregrammatical history (...) Cinema, lacking a conceptual, abstract vocabulary, is powerfully metaphoric; as a matter of fact, a fortiori it operates immediately on the metaphoric level. Particular, deliberately generated metaphors, however always have some quality that is inevitably crude and conventional (Pasolini 1988, 171-174).

Na filmografia do Recife, as ações e os objetos relacionados a uma expressão de grupo constituem, tanto uma objetivamente composta representação visual do sentimento compartilhado, como uma metafórica e complexa subjetividade do afeto originado pelos participantes da cena.

\section{Articulações entre Música e Cinema}

Do ponto de vista da criação, a produção dos sons e das imagens no cinema, de um modo geral, é feita separadamente. O diretor e o compositor criam um mundo, cada qual com suas características intrínsecas a matéria sonora e visual e que só será representado em sua forma final, na sala escura isolada e acústica (Flores 2014, 9).

O processo de produção sonora de uma obra típica de ficção é composta por: diálogos, efeitos sonoros (paisagem sonora e efeitos especiais) e música. Nesta comunicação, o nosso foco de interesse é a música: a trilha musical usada como música de fundo, atmosfera emocional, leitmotiv etc. Músicas pré-existentes, que impulsionam uma composição visual. Músicas que podem desencadear uma variedade de sentidos, como afirma Kathryn Kalinak (2010)

Film music, whether it is a pop song, an improvised accompaniment, or an originally composed cue, can do a variety of things. It can establish setting, specifying a particular time and place; it can fashion a mood and create atmosphere; it can call attention to elements onscreen or offscreen, thus clarifying matters of plot and narrative progression; it can reinforce or foreshadow narrative developments and contribute to the way we respond to them; it can elucidate characters' motivations and help us to know what they are thinking; it can contribute to the creation of emotions, sometimes only dimly realized in the images, both for characters to emote and for audiences to feel (Kalinak 2010, 1).

Ao mesmo tempo em que a música (popular) no cinema, sob a ótica da recepção, incentiva a absorção do aparato tecnológico da imagem pelo espectador, do ponto de vista da produção, a utilização da trilha musical amplia o uso das possibilidades criativas em filmes contemporâneos realizados dentro do contexto das cenas musicais.

As percepções sonora e visual, quando comparadas, são de natureza muito mais díspares do que se imagina. No contrato audiovisual, estas percepções se influem mutuamente, e se prestam uma a outra, por contaminação e projeção, suas respectivas propriedades (Chion 2003).

A experiência de cooperação mútua entre os cineastas e músicos na cidade do Recife (em videoclipes, curtas e documentários), desencadeou uma maneira de realizar filmes narrativos que exploram, de modo deliberado, todo o potencial e referências de um universo musical compartilhado. A mimetização da cena musical do Manguebeat inspirou um cinema mais "musical", gerando uma nova sensibilidade para trabalhar os fenômenos sonoros nos filmes de ficção, intensificando o uso de canções como trilha sonora. Graças à articulação entre realizadores e músicos, o universo da música 
pernambucana reaparece na adoção de uma certa ostentação musical ou, em outros termos, exibição da música (a música como regente dos procedimentos de articulação das linguagens).

Nos filmes Baile Perfumado (1997) e Árido Movie (2006), por exemplo, observamos, recorrentemente, a existência de sequências que poderíamos chamar de "momentos musicais". Essas sequências podem estar incorporadas ao enredo (como parte do percurso narrativo geral) ou podem ser dotadas de maior autonomia em relação à própria ação dramática (marcadas por um certo "deslocamento" do enredo). Em uma outra situação, as sequências se caracterizam por atualizarem momentos "pop" em que o filme para, em função de mostrar a música. Nos "momentos musicais", o tratamento conferido à música nos filmes é comparável aos musicais e videoclipes. Com isso, a música chama atenção sobre si mesma e ganha um estatuto, nesses filmes, mais especial. Diferentemente dos filmes narrativos em geral, nos "momentos musicais", em Baile Perfumado e Árido Movie a música não fica em segundo plano, nem é tão somente uma trilha sonora sem a preocupação de tornar a retórica musical reconhecível pelo espectador (Machado 1997, 152). Ao analisar os filmes acima mencionados, observamos sequências em que os fenômenos de exibição da música são mais evidentes pelos procedimentos da montagem técnica, a música rege o ritmo dos cortes e a duração dos planos; e linguagem de câmera, caracterizada por um virtuosismo imagético (Nogueira, 2010).

As cenas musicais da cidade de Recife, desde a retomada da produção cinematográfica desencadeiam novas formas de apropriação e produção de linguagem audiovisual.

\section{A Música nos Filmes}

Na construção narrativa dos filmes contemporâneos produzidos na cidade de Recife, as demonstrações afetivas/musicais, estão presentes desde a ideia inicial do roteiro, como também na escolha do elenco. Pontuamos abaixo algumas manifestações afetivas previamente arranjadas relacionadas ao universo musical. A partir de uma visão panorâmica dos filmes, que vão da Retomada ao Cinema Contemporâneo, observamos as pequenas homenagens que dão vida à brodagem e à cena audiovisual local, por meio da citação da cena, dos amigos e dos filmes dentro dos filmes. São também marcas estilísticas ${ }^{3}$ do cinema pernambucano que permanecem incrustadas nos filmes e a cada nova obra se reafirmam e se repetem.

Para Michel Chion (2016), a exibição no cinema não é apenas uma mostra de sons e imagens. É um conjunto de sensações temporais, táteis, e rítmicas que usam os canais visual e sonoro. As mudanças provocadas pelos aparatos técnicos da produção audiovisual e exibição ampliam a sensorialidade dessas obras.

Ao observarmos por exemplo os períodos de produção cinematográfica que coexistiram com movimentos musicais é possível notar uma predileção para dar outros sentidos a utilização da música nos filmes. Não mais como reiterações óbvias ou objetivas, mas sim como parte da narrativa fílmica, com sequências planejadas para as músicas. Essa prática foi intensificada principalmente a partir do cinema norte-americano na década de 60.

Nesse sentido, o diálogo entre a canção, com seus movimentos, obras e artistas que configuraram a singularidade sonora da produção musical no Brasil e a produção cinematográfica brasileira a partir da década de 60 produz desdobramentos estilísticos gerando novas maneiras de articulação entre música e imagem.

Para Jeff Smith (2013), a música popular é um potente produto auxiliar na publicidade da indústria cinematográfica. Concretiza-se um esquema de promoção, dentro do qual a música explicita sua referência ao filme. Por outro lado, em certos filmes essa música (parte de um contexto de uma cena cultural) ganha um potencial na criação da imagem. Ao ser exibida nesses filmes, a música chega a deter o desenvolvimento da ação dramática, provocando quase uma "paralisação" do percurso narrativo ou, em outros termos, fazendo a própria história esperar um pouco para avançar em prol de uma determinada atuação ou performance musical.

A inserção dos realizadores, roteiristas, fotógrafos, cenógrafos, músicos nos filmes faz deles o acontecimento que alimenta a própria ideia de grupo. Os realizadores procuram constituir-se como personalidades do universo cinematográfico que parte de uma cena cultural de Pernambuco, sustentando essa construção, através das suas aparições e dos seus amigos nos filmes de produzir um discurso sobre si próprio.

No Baixio das Bestas (2006), o personagem Maninho (Irandhir Santos) caminha em direção a sua casa, assobiando a música tema do filme Amarelo Manga. A intenção de remeter ao universo cinematográfico do próprio Claudio Assis é clara e já pode ser observada desde o próprio Amarelo Manga (2003), quando, por Dunga, personagem do ator Matheus Nachtergaele, cantarola a música tema do filme em uma das faxinas no Hotel.

Este recurso de citação a partir da música é também observado em Era Uma Vez Eu, Verônica (2012), de Marcelo Gomes. Na cena do carnaval em Olinda, onde Verônica se esbalda na celebração da carne, o frevo interpretado pela Orquestra Último Dia, do maestro Levino Ferreira, é o mesmo do seu curta-metragem Clandestina Felicidade (1998), codirigido com o diretor de Arte, Beto Norma. O filme traz fragmentos da infância da escritora Clarice Lispector, quando morou no Recife. Clarice está na janela de uma casa, quando vê um bloco de carnaval passando.

Outra característica recorrente, nesses filmes, é a presença dos músicos pernambucanos nas sequências, configurando um tributo claro à cena musical local do Manguebeat e posteriormente da cena do Pós-mangue ${ }^{4}$, que emergem junto com a criação das narrativas cinematográficas. No Baile Perfumado (1997), Fred 04, líder da banda Mundo 
Livre SA., faz o personagem de um jornalista; Ortinho, um dos compositores da música tema do filme, Sangue de Bairro, é um dos cangaceiros do bando de Lampião, assim como Roger, ex-proprietário do bar Soparia onde a cena Manguebeat foi iniciada, que faz o papel de Corisco no filme. Há também cenas em que os próprios músicos aparecem executando suas canções, como o músico Siba e a banda Mestre Ambrósio, tocando para o bando de Lampião no Baile Perfumado (Nogueira 2010, 125).

O compositor Fred 04, autor do primeiro manifesto do Manguebeat, aparece novamente no filme Amarelo Manga (2003), dessa vez em um plano-sequência em que comanda uma roda de samba no bar, ao som da música de sua autoria, Édipo, o homem que virou veículo, do terceiro álbum da banda, de 1998, chamado Carnaval na Obra.

A cantora Karina Buhr, remanescente do Manguebeat, ex-vocalista do grupo Cumadre Florzinha, apresenta sua performance em uma casa noturna em Era Uma Vez Eu, Verônica (2012). A cantora interpreta a música, Mira Ira, de sua autoria. A sequência, um plano médio da cantora, no seu corpo estão direcionadas as cores luzes, e da sua música, ouvimos a síntese das emoções contidas de Verônica: "Tá tudo padronizado no nosso coração / nosso jeito de amar pelo jeito não é nosso, não." A cantora olha para a câmera, convocando o espectador para celebrar a melancolia.

$\mathrm{Na}$ filmografia esboçada pelo cinema contemporâneo em Recife, os afetos estão suspensos, em suspensões narrativas e fluxos temporais, seja: na aparição dos músicos da cena musical como personagens; na remissão ao universo musical local entre filmes; nas performances narrativas-musicais dos músicos e personagens (momentos musicais); no virtuosismo-imagético potencializado pela música. A partir daqui vamos nos deter na análise de sequências do filme Tatuagem (2013), de Hilton Lacerda, em como esse universo musical é mimetizado pela narrativa.

\section{Suspensão Narrativa e Fluxo Temporal em Tatuagem (2013)}

$\mathrm{Na}$ abertura do filme Tatuagem, um lento planosequência desvenda um lugar em ruínas, pouco iluminado e colorido. Ao fundo, uma voz over convida para um espetáculo: "A mais nova noite do Recife! A noite que abala o quarteirão e faz tremer toda forma de autoridade! A Moulin Rouge do Subúrbio! A Broadway dos pobres! O Studio 54 da favela! Bem-vindos ao Chão de Estrelas!" Muitos aplausos. Corta. Um jovem sentado em uma cama, pensativo. A câmera se afasta à medida que a trilha ganha mais altura e sonoridade. A mistura de sons de guitarra ganha vida no inconsciente do personagem, na confusão de pensamentos que permeiam sua mente. A música é cortada bruscamente pela batida da porta. Um tenente, num estilo Nascido para Matar, de Stanley Kubrick, entra e avisa que o pelotão tem três minutos para chegar ao pátio. Os soldados se apressam para sair do quarto. Corta.

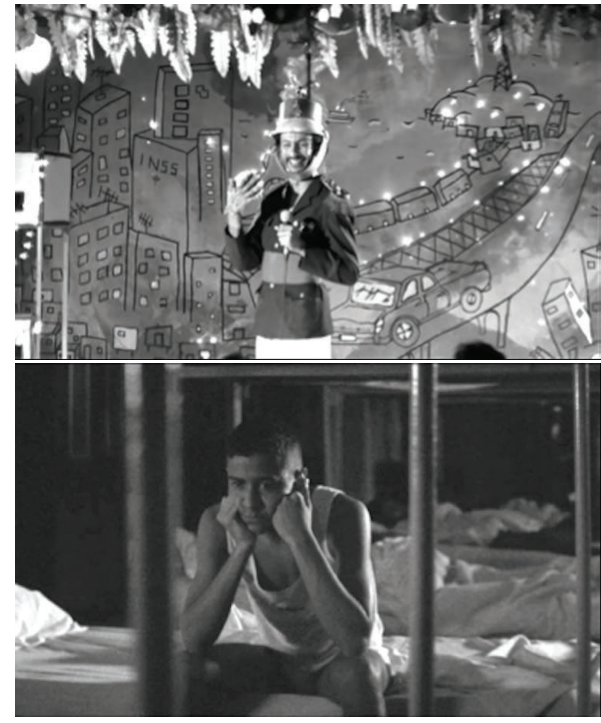

Figuras 1 e 2 - O teatro e o quartel. Fonte: Tatuagem 2013.

Nordeste do Brasil, 1978, a ditadura militar ainda atua no país. Um grupo de artistas, conhecido como Chão de Estrelas, provoca a moral e o poder com seus espetáculos e interferências públicas. Em um teatro/ cabaré, localizado na periferia entre duas cidades, o grupo, juntamente com intelectuais e artistas, ensaia a resistência política a partir do deboche e da anarquia. É dentro desse contexto histórico e social que Hilton Lacerda, constrói o romance entre Clécio (Irandhir Santos) e Fininha (Jesuíta Barbosa). Clécio, o líder do grupo Chão de Estrelas e um jovem militar do interior que presta serviços na capital. Entre o profano, o sagrado e o censurado, as várias narrativas dos personagens, do grupo Chão de Estrelas e dos núcleos familiares, são entrelaçadas a partir da música.

Tatuagem (2013) é o primeiro longa-metragem de ficção de Hilton Lacerda. O diretor e roteirista pernambucano foi responsável pelos roteiros dos filmes Baile Perfumado, Amarelo Manga, Baixio das Bestas, Árido Movie, acima mencionados e também pela codireção (com Lírio Ferreira) do longa Cartola: Música para os Olhos (2007).

A relação do diretor com música remete ao início de sua carreira. Na década de 1990, Hilton Lacerda inicia o projeto Dolores \& Morales, juntamente com Helder Aragão ${ }^{6}$ (Dj Dolores). A dupla é responsável pela capa do disco "Da Lama ao Caos" de Chico Science \& Nação Zumbi. E também pela realização de diversos videoclipes para músicos da cena Manguebeat, entre eles "Homero Junkye", da banda Mundo Livre S/A, e "Etnia", da banda Loustal, de Chico Science. Da trajetória individual ligada a história do Manguebeat e da visualidade que ecoava dos primeiros acordes de guitarra e dos tambores de maracatu, foi se desenvolvendo esse cinema narrativo musical. Um cinema intermediado pela 
música, na construção das sensações temporais, táteis e rítmicas.

Em entrevista concedida aos diretores Lúcia Nagib e Samuel Paiva, para o filme-ensaio Passages ${ }^{7}$ (2019), Hilton Lacerda relata:

A trilha do filme está ligada à construção do roteiro. O filme funciona como uma espécie de opereta. Seria uma nova leitura de uma possibilidade de musical. As letras das músicas estavam escritas no roteiro no sentido de indicação e ganhavam um novo corpo. Helder além de ser o diretor musical do filme fazia as composições e trazia os temas que tivessem haver com aquilo. Uma das questões mais importantes na questão do roteiro e da narrativa é a trilha sonora. (Hilton Lacerda 2019)

A questão sonora foi pensada e trabalhada de forma orgânica no filme. Uma intensa decupagem do som foi realizada de maneira conjunta entre o técnico de som, o diretor musical, o diretor e demais integrantes da equipe. Desde da criação do roteiro, da produção (filmagem), ao processo de pós-produção, a narrativa estava sendo guiada pelo fluxo musical e teatral dos espetáculos do Chão de Estrelas (Santos 2014).

Em Tatuagem, tudo se encaixa numa intensa fluidez: a cor, o som, o movimento, a música, os personagens. A câmera é conduzida com virtuosismo ao longo dos planos sequências. As imagens pictóricas e granuladas, das paisagens em Super-8 servem como transição ao longo da narrativa. Trazem para dentro: os coqueiros, os raios, o vento, a cidade e a estátua, para a década de 1970. O filme é repleto de planos gerais com o núcleo de personagens em quadro. Ações acontecem em primeiro e segundo plano ao mesmo tempo, onde ouvimos todas as vozes dos personagens em cena (algo que lembra muito A Festa da Menina Morta, dirigido por Matheus Naschtergaele) a cidade do interior de Fininha tem o clima da cidade do Baixio das Bestas.

A trilha sonora é composta por quinze músicas préexistentes e dez músicas originais. A primeira cena musical ocorre aos nove minutos do filme. A execução da música (não diegética), "Fui Humilhado" da banda Academia da Berlinda. Esse primeiro momento musical funciona como curto videoclipe com diferentes planos de Clécio e Paulete (Rodrigo Garcia) se divertindo na praia. A música invade a narrativa pela segunda vez aos doze minutos do filme, é a Ave Maria, de Franz Schubert, apresentando a família de Fininha. A música funciona como uma réplica dos personagens, intercalando as narrativas de apresentação do universo dramático de Clécio e Fininha. Até o grupo Chão de Estrelas tomar a narrativa com suas apresentações.

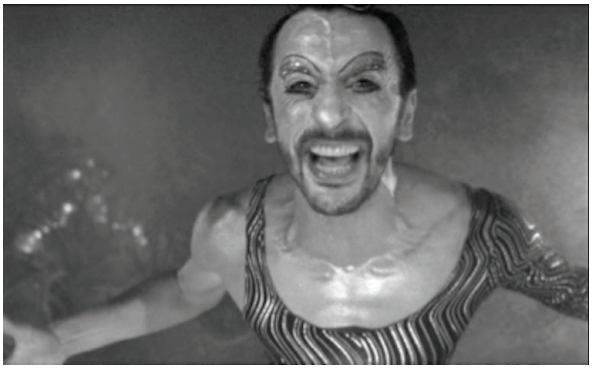

Figura 3 - Corpo e cor no Chão de Estrelas. Fonte: Tatuagem 2013.

Os espetáculos do Chão de Estrelas ultrapassam a tela. Os corpos dos personagens do Chão de Estrelas têm seus movimentos visualmente intensificados por uma câmera que os acompanha como um parceiro no palco. As cenas internas têm pouca luz e muita cor, a poesia visual está na perfeita harmonia entre a fotografia e a arte. Os planos-sequências e os movimentos circulares tornam os movimentos dos corpos de suas personagens ações expressivas que articuladas ao som do filme provocam verdadeiras suspensões narrativas. No limiar de uma estética relacional, o espectador se desloca para aquele ambiente. A encenação transforma os corpos em acontecimentos, experiências vivas. Há uma manipulação da textura cinemática dos corpos em torno dos sentimentos.

As interpretações musicais são verdadeiras suspensões temporais, como na apresentação do cantor e compositor Johnny Hooker, cantando Volta, música de sua autoria. A música é executada ao vivo e define o ritmo dos movimentos da câmera e preenche a atmosfera do teatro/cabaré. As cores azul, vermelha e verde ocupam o espaço. Fortes e contrastadas evidenciam as ruínas do lugar e o estado de espírito do grupo. A casa de espetáculos do Chão de Estrelas é o lugar do sentimento.

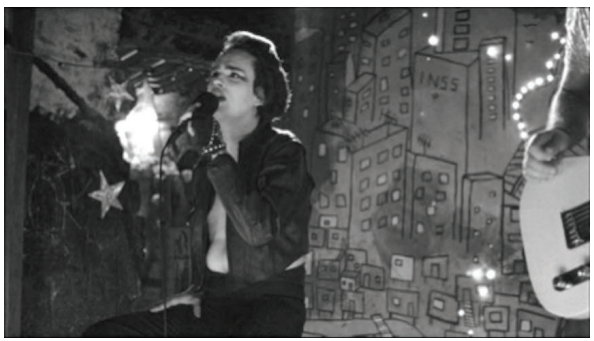

Figura 4 - Johnny Hooker interpreta a sua música intitulada "Volta". Fonte: Tatuagem (2013)

Outra suspensão temporal na sequência. A apresentação musical de Clécio é antecipada pela apresentação do filme, Prosopopéia Herética, em Super-8, com poesia narrada por Clécio.. O palco está escuro. A única fonte de luz é da imagem projetada. Contraluz do corpo de Clécio. O som das cordas de 
um violão. Uma luz é direcionada a Clécio, no palco vestido de brilhos e um casaco de pele, com flor no cabelo, calça dourada colada, acende.

Clécio levanta, à medida que canta Esse Cara (música de Caetano Veloso, conhecida pela interpretação de Maria Bethânia). Clécio interpreta a música numa performance de conquista. Ao final da interpretação, mantém os olhos fixos em Fininha, que está na plateia. Referência do rosto de Fininha desfocado em primeiro plano. Ao fundo Clécio o mira envolventemente. Fininha é invadido pelo brilho envolvente de Clécio. O instante dos dois é bruscamente rompido pelos aplausos à interpretação de Clécio.
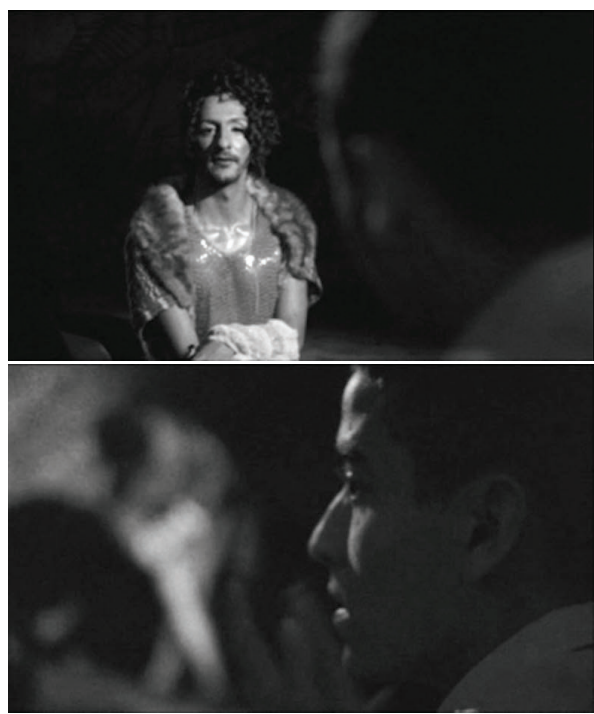

Figuras 5 e 6 - O afeto, suspenso pelo olhar.

Fonte: Tatuagem 2013.

O ator recebe os aplausos desconcertado. Fininha, com o rosto agora focado, evidencia uma ansiedade.

A partir do primeiro encontro entre Clécio e Fininha, a trilha sonora funciona como a personagem que embala o romance do casal. Entre a anarquia dos espetáculos do teatro cabaré, em meio aos cômodos do casarão do Chão de Estrelas, a música interpretada por Dolores Duran, é bailada intimamente por Clécio e Fininha e tem toda a intensidade de um segundo encontro. São opostos (o soldado e o ator) que se aproximam a cada passo dado.

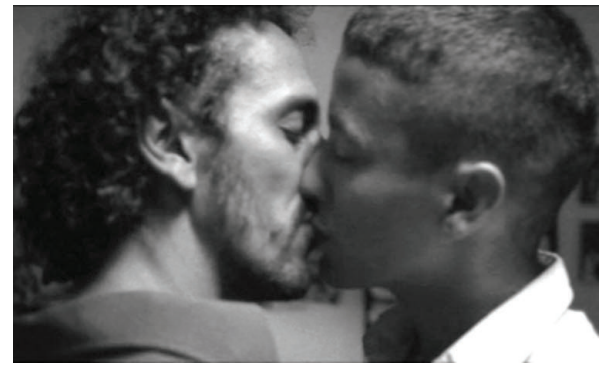

Figura 7 - A contradança de Clécio e Fininha.

Fonte: Tatuagem 2013.

O plano-sequência tem início na radiola onde Clécio põe um disco. A música, A Noite do Meu Bem, interpretada por Dolores Duran, envolve o ambiente. Fininha o observa pelas frestas da janela, caminha até a sala. Um diálogo sobre os nomes dos dois se estabelece. Clécio, sempre num tom sensual provocativo, convida Fininha para dançar. Trocam algumas palavras no entrelace dos corpos envolvidos pelo movimento. Clécio se apossando pouco a pouco do corpo de Fininha. Fininha demonstra curiosidade. A partir dali, percebemos que o encontro dos corpos já foi comungado. Clécio pergunta a Fininha: Tu já beijou um homem? Fininha olha para os lábios de Clécio e o beija. Tatuagem é corpo, cor, música e afeto.

Os próximos encontros do casal são marcados por momentos de discussão, movimentos, paixão e celebração. Fininha ajuda na mudança para o casarão, participa das festas e se envolve com Érico, um dos atores da trupe. Clécio é possuído de ciúme por Fininha. Os encontros dos dois amantes expõem a dificuldade em viverem juntos. Há uma evidente incompatibilidade entre a construção da liberdade e a ditadura militar, entre o amor e o real.

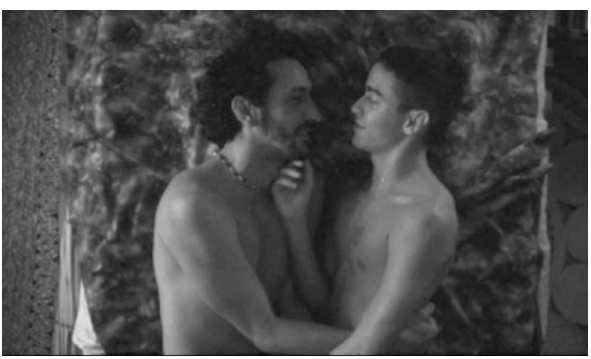

Figura 8 - O romance entre Clécio e Fininha.

Fonte: Tatuagem 2013.

Em Tatuagem, a intensidade do afeto que exala dos corpos cinematográficos se põe ao espectador. No desvio, no dissenso, nos opostos. O afeto está nas cores, luzes e no brilho do cabaré. Na organicidade da câmera circular permite ao espectador observar com fluidez os espaços. Na música que preenche toda a atmosfera e extrapola a sensorialidade da imagem.

O filme termina com a exibição dos filmes do professor Joubert (Sílvio Restiffe), personagem 
inspirado no cineasta Jomard Muniz de Britto ${ }^{8}$. Ao ser questionado, por uma repórter, sobre o filme que vai exibir, Ficção e Filosofia, Joubert responde: "O mais importante não é o que as pessoas vão ver, mas o que elas deixarão de ver".

A poesia do cinema está fora do filme, no que não está visível aos olhos, no que não percebemos subjetivamente, naquilo que não podemos mensurar. Nas suspensões poético narrativas, no fluxo temporal sonoro e visual. Ali está o afeto. A consumação do encontro amoroso, entre Clécio e Fininha, sugere a transcendência do afeto em relação ao humano e ao mundo. Tatuagem, mais do que sentimentos ou afetos, é um filme sobre amor. Como diziam os cartazes do filme colados nos postes das cidades, onde o filme estreou: "Tatuagem. Traz o amor de volta em 90 minutos."

\section{Conclusão}

Ao observarmos como a retomada da produção cinematográfica na cidade de Recife vai coexistir com a eclosão da cena musical do Manguebeat é possível notar uma predileção para trazer esse universo musical em prol de uma interpretação audiovisual. Não como reiterações óbvias ou objetivas, mas sim como parte da narrativa fílmica, com sequências criadas para as músicas.

No cinema contemporâneo em Pernambuco há uma assimilação do fenômeno musical no contexto da criação artística dos filmes. O cruzamento das cenas da música e do cinema, produz desdobramentos estilísticos na montagem dos filmes. A música é incorporada pela narrativa como parte de uma experiência visual performática. Os filmes são dotados de "momentos musicais", de fluxos temporais regidos por um virtuosismo sonoro-imagético e de suspensões da narrativa para exibição da música.

Tais "momentos musicais" podem ser relacionados com a visão sinestésica do cinema de montagem de Eisenstein (1990), na qual elementos característicos de cada natureza são combinados de maneira única. Dessa forma, a música, a fotografia, a mise-en-scène são associados em prol de uma experiência sinestésica.

Já no âmbito na narrativa fílmica, os momentos musicais, ao serem articulados pela montagem, podem ser compreendidos como uma narrativa alternativa dentro desse processo. A trilha sonora, para além de articular os elementos expressivos de distintas natureza é também elemento privilegiado na proposição das organizações temáticas e na construção espaço temporal. Entre os usos esperados e inesperados da articulação entre os fenômenos, visual e sonoro, desenvolve-se uma montagem mais musical no cinema recifense contemporâneo.

\section{Notas finais}

${ }^{1}$ Termo utilizado para designar a cena musical pernambucana que surgiu na década de 90 na cidade do Recife, que mistura ritmos regionais com rock, hip hop e música eletrônica e que teve como percursores as bandas Chico Science \& Nação Zumbi e Mundo Livre S/A, entre outras.
Estamos tratando nessa comunicação da produção referente à um grupo de cineastas que começou a realizar cinema na cidade do Recife a partir da década de 80 e os quais estiveram envolvidos na realização do filme Baile Perfumado e consequentemente na retomada do cinema pernambucano, do qual fazem parte: Adelina Pontual, Claudio Assis, Hilton Lacerda, Lírio Ferreira, Marcelo Gome e Paulo Caldas.

${ }^{3}$ Sobre marcas estilísticas do cinema em Pernambuco cf. Nogueira 2010.

${ }^{4}$ Pós-mangue é a cena musical alternativa que surgiu a partir dos anos 2000, de sonoridades completamente distintas, provindas do indie, rocker, psicodélico, entre tantos outras. São expoentes do Pós-mangue: Mombojó, Volver, Johnny Hooker, A Comuna etc. Sobre o Pós-Mangue cf. Maia Jr. 2012.

${ }^{5} \mathrm{O}$ cantor e ator Johnny Hooker nasceu na cidade do Recife em 1987. Ganhou o Prêmio da Música Brasileira como Melhor Cantor na categoria Canção Popular no ano de 2015. Compôs a música "Volta" à pedido do diretor Hilton Lacerda para o filme Tatuagem.

${ }^{6}$ Helder Aragão, conhecido como DJ Dolores é o autor da trilha original de Tatuagem.

${ }^{7} \mathrm{O}$ filme-ensaio Passages: travelling in and out of film through Brazilian geography (2019), dirigido por Lúcia Nagib e Samuel Paiva, propõe uma reflexão sobre a produção que emerge no Brasil a partir da Retomada do Cinema Brasileiro. As entrevistas com os realizadores estão disponibilizadas na íntegra no website do Intermidia Project: https://research. reading.ac.uk/intermidia/passages/

${ }^{8}$ Jomard Muniz de Britto é escritor, agitador cultural e um dos mais prolíficos realizadores em Super 8 de Pernambuco. Participou do movimento tropicalista nos anos 70 e manteve uma forte ligação com o grupo Vivencial Diversiones, no qual foi inspirado o grupo Chão de Estrelas.

\section{Bibliografia}

Bazin, André. 2013. Pour un cinéma impur - défense de l'adaptation. In Qu'est-ce que le cinéma? Paris: CERF, 81-106.

Chion, Michel. 2016. A audiovisão : som e imagem no cinema. Traduzido por Pedro Elói. Lisboa : Texto \& Grafia. . 2003. Film Sound as Art. Traduzido do francês por Claudia Gorbman. New York: Columbia University Press.

Eisenstein, Sergei. 1990. O Sentido do Filme, Rio de Janeiro: Jorge Zahar Editor.

Flores, Virginia. 2013. Além dos limites do quadro: o som a partir do cinema moderno. Tese de Doutoramento, Universidade Estadual de Campinas.

Kalinak, Kathryn. 2010. Film Music: A Very Short Introduction. New York: Oxford University Press.

Machado, Arlindo. 1997. Pré-cinemas e pós-cinemas. Campinas, SP: Papirus.

Maia Jr., Ricardo. 2012. Entrelugares: notas críticas sobre o pós-mangue - Recife: José Juvino da Silva Júnior.

Nogueira, Amanda M. C. 2014. A Brodagem no Cinema em Pernambuco. Tese de Doutoramento, Universidade Federal de Pernambuco.

2010. O novo ciclo de cinema em Pernambuco: a questão do estilo. Recife: Editora Universitária.

Pasolini, Pier Paolo. 1988. Heretical Empiricism. Editado por Louise K. Barnett. Michigan: Indiana University Press.

Santos, Marcos. 2012. Tatuagem: de dentro para fora, um estudo do processo de criação a partir do roteiro do filme. Dissertação de Mestrado, Universidade Federal de Pernambuco.

Sennett, Richard. 2012. Juntos. Os rituais, os prazeres e a política da cooperação. Rio de Janeiro: Record.

Smith, Jeff. 2013. The Sound of Intensified Continuity. 
In The Oxford Handbook of New Audiovisual Aesthetics. Organizado por John Richardson, Claudia Gorbman e Carol Vernallis. New York: Oxford University Press.

Straw, Will. 2002. Cities/Scenes. Toronto: Public Access/York University.

\section{Filmografia}

Amarelo Manga. 2003. De Claudio Assis. Brasil: California Filmes. DVD.

Árido Movie. 2006. De Lírio Ferreira. Brasil: Europa Filmes. DVD.

Baile Perfumado. 1997. De Paulo Caldas e Lírio Ferreira. Brasil: Imovision. DVD.

Baixio das Bestas. 2006. De Claudio Assis. Brasil: Imovision. DVD.

Cartola: Música para os Olhos. 2007. De Hilton Lacerda e Lírio Ferreira. Brasil: Europa Filmes. DVD.

Clandestina Felicidade. 1998. De Marcelo Gomes e Beto Normal. Brasil: Cinemateca Pernambucana. Online.

Entrevista com Hilton Lacerda para o filme Passages. 2019. De Lúcia Nagib e Samuel Paiva. Intermidia Project. Online.

Era uma vez eu, Verônica (2012). De Marcelo Gomes. Brasil: Imovision. DVD.

Tatuagem. 2013. De Hilton Lacerda. Brasil: Imovision. DVD. 